\title{
Autorregulación y desarrollo de capacidades que incrementan la coherencia entre juicio y acción
}

\section{Silvia López}

\section{$\mathcal{D} \mathcal{M a}$}

El desarrollo de las competencias autorreguladoras de la persona adquiere una especial importancia cuando se trata de incrementar la coherencia entre juicio y acción. En este artículo se analizan los conceptos de autorregulación y autocontrol así como las diferentes consideraciones que puedan ayudar a su contextualización en el aula. Se propone una actividad para el primer ciclo de Educación Primaria.

\section{INTRODUCCION}

Una de las dimensiones más importantes de la acción pedagógica en el ámbito de la educación moral, es la de orientar el desarrollo de competencias y conductas que supongan un alto nivel de autorregulación y autocontrol en el alumno/a. El desarrollo de estas capacidades puede suponer una mayor coherencia entre juicio y acción, entre pensamiento y conducta, ya que la finalidad de las mismas, es que la persona reflexione sobre su conducta y establezca pautas de acción para mejorarla.

La autorregulación no se consigue si la persona no dispone de los medios necesarios para influir sobre su propia conducta, conociendo las fuentes de influencia de la misma, sean de carácter externo o generadas por el mismo individuo. Esto hace necesario la formación de las personas para que estén capacitadas para regular, de forma autónoma, su conducta y su actuación en el entorno donde viven, a la vez que están preparadas para presentar conductas singulares, basadas o/y orientadas en criterios personales.

Algunas de las razones del interés manifestado por algunos investigadores terapéuticos hacia el estudio de la autorregulación son las siguientes: es necesario que la persona pueda actuar con independencia de los factores extrínsecos, de la dirección y manipulación externa; los educadores y padres no pueden controlar todo el ámbito de interrelación de los niños/as, con lo que uno de los ob- 
jetivos de la educación ha de ser enseñar a autorregularse; si el alumno/a es capaz de autorregular y autocontrolar su conducta, puede producir en él, cambios más durables y generalizables. Para vivir en una sociedad democrática no es suficiente que la persona actúe de acuerdo con aquello que piensa, sino que también deberá respetar y asumir las normas y roles sociales, sin los cuales no sería posible una convivencia armónica. Pedagógicamente, el desarrollo y potenciación de procesos de autorregulación y autocontrol en el alumno/a puede contribuir, a largo plazo en su proceso de socialización, proceso que no ha de ser únicamente adaptativo, sino que ha de tener un carácter proyectivo, basándose en juicios de valor y criterios personales, pero sin olvidar la importancia de aceptar ciertos valores y normas considerados como necesarios para la convivencia y el desarrollo de la persona en su dimensión social. La autorregulación y el autocontrol permitirán a la persona conseguir los objetivos personales que mejoran su conducta y que pueden colaborar en un mejor autoconcepto y un grado de autoestima superior.

\section{CONCEPTOS Y OBJETIVOS DE AUTORREGULACION $Y$ AUTOCONTROL DE LA CONDUCTA}

Se entiende por autocontrol aquel proceso comportamental, de carácter continuo y constante, en el que la persona es la máxima responsable de su conducta. Para que el individuo sea capaz de presentar este comportamiento es necesario, como ya hemos mencionado, que conozca las variables externas e internas que influyen en él y sepa manipularlas siempre que sea necesario para conseguir los objetivos deseados.

Por otra parte, el autocontrol se define como aquel resultado comportamental consistente en no llevar a cabo una respuesta de alta probabilidad; es decir, supone un proceso de autorregulación en que la respuesta no solamente está determinada por la persona, sino que además es poco probable que se produjera sin el concurso de esta.

De lo dicho hasta el momento, puede desprenderse que mediante la enseñanza de las técnicas de autorregulación en la escuela se pretende formar o autoformar al alumno para que sea capaz de actuar en conformidad con un mundo de valores objetivamente válidos y, para que tenga una actitud crítica frente a determinadas formas de vida del mundo de los adultos. Desde este punto de vista, las estrategias de autocontrol y autorregulación de la conducta están orientadas a:

- Ayudar al alumno/a a comportarse en función de criterios propios,- generados por la propia persona, consensuados o escogidos desde fuera

- Ayudar a equilibrar posibles disarmonías o faltas de la propia conducta.

\section{ESTRATEGIAS ORIENTADAS AL DESARROLLO DE LAS COMPETENCIAS AUTORREGULADORAS EN EL ALUMNO}

Las diferentes estrategias que se proponen para desarrollar estas competencias se pueden agrupar en dos bloques:

a) Actividades orientadas para trabajar las condiciones necesarias a todo proceso de autorregulación en presencia del profesor. Son actividades que procuran desarrollar en el alumno habilidades y destrezas orientadas a facilitar y 
optimizar el autocontrol en los ámbitos social y escolar. Son programas de acción pedagógica que permiten aprender técnicas de autodeterminación de objetivos, autoobservación y autorefuerzo. Estas tres técnicas pueden ser consideradas como tres fases fundamentales dentro del desarrollo de las competencias autorreguladoras.

b) Actividades que suponen la práctica de la autorregulación por parte del alumno. Suponen un desplazamiento del protagonismo del profesor hacia el alumno/a, de tal forma que éste pueda adquirir competencias autorreguladoras no únicamente frente a los problemas escolares y/o sociales. Son actividades agrupadas bajo los términos de ajuste de la conducta, sentido de la responsabilidad, técnicas de autocontrol, autorregulación del estrés, técnicas de autoverbalización...

\section{PROCESO DE AUTORREGULACION Y AUTOCONTROL DE LA CONDUCTA. ASPECTOS PRACTICOS}

Para trabajar pedagógicamente la capacidad de autorregulación es necesario:

a) Motivar a la persona, concienciarla para que sea ella la que decida modificar su conducta.

b) Enseñarle y hacer que autopractique las técnicas de autorregulación y autocontrol, como por ejemplo: autobservarse, registrar datos, control de los estímulos antecedentes que ponen en marcha la conducta, técnicas de refuerzo positivo,...

Podemos decir que estamos delante de un proceso de autorregulación y autocontrol de la conducta cuando la persona sigue los siguientes pasos:

1. Reconocer que se encuentra en una situación problemática.

2. Darse cuenta de que se está rodeado de variables que pueden causar conductas incontroladas. Analizar el medio y determinar qué aspectos pueden producir esa situación.

3. Formular un plan para prevenir su mal comportamiento. El plan establecido ha de ser capaz de alterar el medio ambiente, reduciendo la influencia de las variables que producen la conducta desviada.

4. Realización del plan y autoevaluación.

La enseñanza de estas capacidades autorreguladoras requiere la utilización de diversas técnicas, algunas de las cuales ya hemos mencionado anteriormente y, otras tan conocidas como los dilemas morales, role-playing, clarificación de valores...

A continuación se presenta - a propósito de una actividad concreta- el proceso que puede seguir el/la educador/a para trabajar el proceso de autorregulación en el aula con niños de 6-8 años. El ejemplo que proponemos corresponde al ámbito temático «Relación entre iguales» donde se analizan los conflictos en la relación con los iguales y sus posibles soluciones intentando que el alumno se de cuenta y reflexione sobre las consecuencias de sus propios actos.

\section{ACTIVIDAD: ARREGLEMOS LAS COSAS}

\section{Reconocer que se encuentra en una situación problemática}

Esta primera fase se ha trabajado, previamente, con otras actividades de la unidad de programación. Son actividades que, mediante dilemas morales (bre- 
ves historias), comprensión crítica (cuento o dibujo), etc., ponen de manifiesto la existencia de conflictos reales que los niños/as viven en su realidad cotidiana, asumiéndolo éstos como una situación que es necesario resolver dadas las consecuencias negativas que comporta.

En otras edades superiores, esta primera fase se puede incluir en la misma actividad de autorregulación como una pregunta más, ya que los alumnos tienen mayor capacidad de abstracción.

Darse cuenta de que está rodeado de variables que pueden causar conductas incontroladas. Analizar el medio y determinar qué aspectos puede producir esa situación

En esta fase se trata de que los alumnos/as descubran las causas, las variables que influyen en su conducta, conducta que a la vez es origen de discusiones y problemas con sus compañeros. Dada la edad de los niños/as que nos ocupan el educador deberá ir ofreciendo ayudas sobre las posibles causas de esos conflictos.

\section{Formular un plan para prevenir su mal comportamiento}

El plan establecido, como ya hemos explicado, ha de modificar el entorno, reduciendo al máximo la influencia de las variables que producen la conducta no deseada. En esta tercera fase hablaríamos de autodeterminación de objetivos: se pretende modificar la conducta en función de objetivos o criterios establecidos. En los niveles evolutivos inferiores los criterios se imponen desde fuera, por parte del profesor. En niveles posteriores, los criterios son autopropuestos por el propio alumno. Para que estas actividades tengan eficacia, los criterios han de reunir tres condiciones:

- Han de colaborar en concentrar la atención del alumno.

- Han de informar a los alumnos de lo que se ha de hacer específicamente.

- Han de proporcionar consecuencias gratificantes o no en función de su rendimiento.

Estas tres primeras fases se concretan en la actividad que presentamos en las siguientes preguntas:

- Piensa en alguna cosa que tu haces y que a veces molesta a tus amigos

- ¿Por qué crees que pasa eso? ¿Por qué haces esa cosa?

- ¿Crees qué podrías hacer alguna cosa para qué eso no pasase? ¿Cuál?

- ¿Cómo prefieres que estén tus amigos contentos o enfadados? ¿Por qué? 


\section{Orientaciones para el educador}

En esta actividad el objetivo es que los alumnos reflexionen sobre su conducta y las consecuencias de ésta en su relación con los amigos/as.

En la primera pregunta de la actividad se intenta hacer un análisis específico y personal, y por tanto es interesante que sea individual. El educador puede ayudar dando algún ejemplo. La segunda pregunta hace referencia a las causas de esa conducta. La tercera pregunta plantea la posibilidad del cambio de conducta. La última cuestión, se puede analizar a nivel del grupo clase, para que entre todos, vayan surgiendo objetivos que hacen más agradable la convivencia y la relación (Autodeterminación de objetivos).

\section{Realización del plan y autoevaluación}

Esta última fase incluiría la autoobservación: ha de permitir al alumno analizar sus comportamientos, seleccionando conductas específicas a observar, determinar la forma y el momento, así como la manera de registrar esta observación. La selección de la conducta a observar ha de estar orientada por dos características fundamentales: ha de ser accesible a la observación y ha de existir objetividad en los sistemas de registro y medición. Una vez identificada la conducta se registra en una ficha tantas veces como se da.

La autoevaluación se trabaja al practicar la autoobservación. El proceso central de la autoevaluación es la comparación entre los objetivos propuestos y los autoobservados en la conducta registrada.

El autorefuerzo tendría su sentido en su efecto positivo para la planificación de estrategias que facilitan el cambio de conducta. La presentación de reforzadores se inicia por parte del educador (refuerzo afectivo y social) y progresivamente se induce en el educando a través de la interiorización de la satisfacción o insatisfacción que el mismo experimenta en función de la adecuación de su conducta.

En la actividad que presentamos, esta cuarta fase se concreta en lo siguiente: - En la ficha siguiente apunta las cosas que haces para que tus amigos no se enfaden y si te ha dado buen resultado.

Lunes

\begin{tabular}{|l|l|}
\hline Hice... & Mis amigos... \\
& \\
& \\
\hline
\end{tabular}

\section{Orientaciones para el educador}

El educador/a propondrá una actividad semanal de observación de la propia conducta y de las consecuencias en la relación con los amigos/as. Conducta que 
se registrará en la ficha que se presenta y que después podrá ser comentada con toda la clase. El refuerzo social y afectivo (compañeros, maestro/a) es muy importante en estas edades.

\section{OTRAS ACTIVIDADES}

\section{Organizo mi tiempo (6. ) Ambito temático: Escuela y trabajo}

La planificación y organización del tiempo de estudio es una tarea que tú mismo o tú misma has de hacer, ya que nadie mejor que tú sabe el tiempo que has de dedicar a hacer los deberes o aprender algo. Para planificar tu horario de trabajo no olvides que cuando estás más descansado/a es mejor que te dediques a las cosas que te resultan más difíciles, dejando para otros momentos aquellas actividades que no requieren mucha concentración y son más fáciles. Piensa también que si te acostumbras a trabajar cada día a la misma hora y estudiar un poco, todo puede resultarte más fácil y agradable.

Para planificar tu tiempo de estudio, no has de olvidar las otras cosas que has de hacer o te gusta hacer durante el día. Así, es importante que en tu plan de trabajo distribuyas el tiempo según las diferentes actividades y tareas que haces.

Antes de hacer tu plan de trabajo, contesta las siguientes preguntas:

1. ¿Cuando llegas a casa qué haces: ver la tele, hacer los deberes u otras cosas?

2. ¿Normalmente repasas los temas o lecciones que habéis hecho en clase durante el día?

3. ¿Preparas los exámenes con tiempo suficiente, o siempre vas deprisa y estudias solo el día antes?

4. ¿Dedicas cada día un tiempo fijo para estudiar y hacer los deberes?

5. ¿Te cuesta ponerte a estudiar? ¿Por qué?

6. ¿Haces otras actividades al salir del colegio? ¿Cuáles? ¿Cuánto?

7. Piensa en el día de ayer y realiza el cálculo del tiempo que dedicaste a las siguientes cosas (en total todo el tiempo ha de sumar las $24 \mathrm{~h}$. que tiene un día):

Dormir

Tiempo:

Comidas (desayunar, comer...)

Tiempo en el colegio

Estudiar y hacer los deberes...

Leer

Otras actividades al salir del colegio (deporte, música...)

Ver televisión

Jugar

Total: $24 \mathrm{~h}$.

8. ¿Crees que el tiempo que dedicas a estudiar y hacer los deberes es suficiente? ¿Por qué?

Elabora un plan de trabajo semanal, explicando el tiempo que dedicarás cada día a realizar diferentes actividades. Piensa en cómo distribuir tu tiempo de forma que cada día dediques un rato a estudiar y hacer los deberes. Al final de cada día pinta de color rojo los horarios que has respetado. Cuando acabe la semana haz una valoración y explica el porqué algunos horarios no los han cumplido. 


\begin{tabular}{|l|l|l|l|l|l|l|l|}
\hline & Lunes & Martes & Miércoles & Jueves & Viernes & Sábado & Domingo \\
\hline Estudiar & & & & & & & \\
\hline Hacer los deberes & & & & & & & \\
\hline Leer & & & & & & & \\
\hline Ver la televisión & & & & & & & \\
\hline Jugar & & & & & & & \\
\hline Otras actividades... & & & & & & & \\
\hline
\end{tabular}

\section{El trabajo de escuela (8. ${ }^{\circ}$. Ambito temático. Escuela y trabajo.}

Horario y estudio

Piensa en la forma como organizas tu trabajo escolar. Quizá hay cosas que iría bien cambiarlas. Aquí te ayudaremos a intentarlo.

- Escribe detalladamente cuantas horas, durante la semana y el fin de semana, tendrías que dedicar al estudio en casa. Distribuye estas horas durante todos los días de la semana.

- En una hoja, escribe tu horario de trabajo personal y cuélgalo en tu habitación. Comienza a aplicarlo hoy mismo.

- En una libreta, anota, como si fuera un diario, si has cumplido el horario que te habías propuesto. Una vez acabado el tiempo de trabajo, describe tus impresiones, comenzando por si piensas que has aprovechado de verdad este tiempo o, por el contrario, te has levantado muchas veces, si se te ha hecho muy pesado o no; si te ha cundido, etc.

- Después de la primera semana, ¿te encuentras satisfecho/a con la forma como lo has llevado a cabo? ¿Crees que has mejorado en el estudio?

- Si quieres, puedes explicar tu opinión sobre la realización de este ejercicio a todo el grupo.

\section{Lunes 8}

Hoy no me ha ido muy bien. La lección de Historia era larga y...

\section{Referencias}

Fabregas, J. J.; Garcia, E. (1989). Técnicos de autocontrol. Madrid: Alhambra.

LÓpez, S. «Autorregulación» en MARTINEZ, M. \& PUIG, J. M. (coord.). (1991). La educación moral. Perspectivas de futuro y técnicas de trabajo. Ed. Graó. ICE Universitat de Barcelona. pp. 121-129.

Pantoja, L. (1986). La autorregulación científica de la conducta: teoría y técnicas aplicadas a la terapia y educación. Bilbao: Universidad de Deusto. 


\section{Autorregulación y desarrollo de capacidades que incrementan la coherencia entre juicio y acción Silvia López \\ CL\&E, 1992, 15, pp. 111-118}

Resumen: Una de las dimensiones más importantes de la ación pedagógica en el ámbito de la educación moral, se debe orientar al desarrollo de competencias y conductas que supongan un alto nivel de autorregulación y autocontrol en el alumno/a. El desarrollo de estas capacidades puede suponer una mayor coherencia entre juicio y acción, entre pensamiento y conducta, ya que la finalidad de las mismas es que la persona reflexione sobre su conducta y establezca pautas de acción para mejorarla.

Es necesaria la formación de la personas de manera que esten capacitada para regular, de forma autónoma, su conducta y su actuación en el entorno donde viven, a la vez que están preparadas para presentar conductas singulares, basadas en criterios personales.

Datos sobre el autor: Silvia López es pedagoga y actualmente goza de una beca de Formación de Personal Investigador del Ministerio de Educación y Ciencia. También es miembro del Grupo de Investigación en Educación Moral (G.R.E.M.).

Dirección: Departamento de Teoría e Historia de la Educación, Facultad de Pedagogía, Universidad de Barcelona, Baldiri Reixac, s/n 08028 Barcelona. Tel (93) 3333466.

(C) De todos los artículos deberá solicitarse por escrito autorización de CL\&E y de los autores para el uso en forma facsímil, fotocopia o cualquier otro medio de reproducción impresa. CL\&E se reserva el derecho de interponer las acciones legales necesarias en aquellos casos en que se contravenga la ley de derechos de autor. 